\title{
A Call for Weather Condition Evaluation in Mega-Events Management
}

\section{Hossein GT Olya}

\begin{abstract}
This letter provides a new insight into knowledge-based management of mega-events by highlighting the significance of weather in destination selection and scheduling events as an adaptive strategy toward climate change. Concerning environmental and socio-economic costs of weather ignorance in event management, which may result in cancelation and change of the event time, it is recommended that planners perform a preliminary study prior to publicizing an event plan. Therefore, the organizer and visitors can benefit from optimal weather in destination, as this study advises the decision-makers of the Tokyo 2020 Olympic and Paralympic Games reschedule the dates of this international event.
\end{abstract}

Keywords: Mega-Events; knowledge-based management; weather; Tokyo $\underline{2020}$.

\section{Introduction}

Weather plays a key role in tourism and event management, as it may influence the attitudinal and behavioural responses of visitors in terms of satisfaction, disconfirmation, comfort, length of stay, and intentions to revisit and recommend the destination (de Freitas, 2015; Olya \& Altinay, 2016). Weather also contributes in tourism site selection, the efficiency and application of infrastructure, the return on an investment, and schedule and location of events (Gómez Martín, 2005; Olya \& Alipour, 2015a). Ignoring weather conditions in event management can lead to unexpected economic, environmental, and social impacts. For example, the sixth stage of the 2017 Dakar Rally was cancelled in Bolivia due to extreme weather conditions (Baldwin, 2017). Similarly, the Rally China round of the 2016 World Rally Championship was cancelled due to weather damage near Beijing in (Evans, 2016). FIFA also acknowledged that awarding the 2022 World Cup to Qatar was a mistake due to the country's hot summers $\left(50^{\circ} \mathrm{C}\right)$, requiring the schedule to be shifted from June and July to late November and December (Blatter, 2013).

\section{Managing of mega-events risks}

$\underline{\text { Mega-events as a complex system is a source of wide range of internal (e.g., traffic volume and }}$ $\underline{\text { transport accidents, fraud, mismanagement, and security issues) and external (e.g., sever }}$ 
weather, international terrorism and cyber-terrorism) risks (Chang \& Singh, 1990; Jennings et al., 2012; Toohey \& Taylor, 2008). Jennings et al. (2012) identified strategies for managing mega-events risks based on lessons from past Olympics. For example, in the case of Calgary's 1988 Winter Olympics, a committee was organized to prepare a formal risks management framework and contingency plans. Organizers sought to manage financial risks using insurance mechanism and hedging instruments. Political risk can be mitigated by diplomacy acts and multilateral protocol. In London 2012, government designed an integrated risk management system at programme-level to cope with safety, health, operation, and services risks. Specifically, organizers developed a resilience plan for controlling epidemic diseases and standardised risk assessment forms for reducing operational and service risks (Jennings et al., 2012). Another lesson from Vancouver 2010 Olympic is systematic ranking and categorizing the risks in three stages of pre-games, games-time, and post-games. Risk of weather should be considered by International Olympic Committee (IOC) at feasibility assessment stage in which host cities go through the bid procedure (Jennings, 2012).

\section{Tokyo 2020 Olympic and Paralympic Games}

There is a paucity of research about setting an ideal schedule for mega-events based on the weather at the destination. Organizing the mega-event at the right time and right place not only acts as an adaptive strategy toward climate change, but also mitigates any potential threats caused by overlooking the weather. This article aims to address this research gap by evaluating the suitability of Tokyo's weather for the 2020 Olympic and Paralympic Games and making a call for considering weather conditions of host destination at an early planning stage of future mega events. The Tourism Climate Index (TCI), which was developed by Mieczkowski (1985), was applied to evaluate the monthly weather conditions of Tokyo using longitudinal data from 1981 to 2010 (Japan Meteorological Agency). Monthly means of seven meteorological factors-namely, maximum daily temperature, mean daily temperature, minimum daily relative humidity, daily relative humidity, precipitation, daily duration of sunshine, and wind speed-were used to calculate the monthly TCI based on formula 1.

$\mathrm{TCI}=8 \mathrm{CID}+2 \mathrm{CIA}+4 \mathrm{R}+4 \mathrm{~S}+2 \mathrm{~W}$ 
CID stands for Daytime Comfort Index, obtained from variables of maximum daily temperature (C) and minimum daily relative humidity (\%). CIA represents Daily Comfort Index, which combines the variables of mean daily temperature (C) and daily relative humidity $(\%)$. $R$ is the mean monthly precipitation $(\mathrm{mm})$, while $\mathrm{S}$ represents the mean monthly hours of sunshine per day. Lastly, $\mathrm{W}$ is the mean monthly wind speed $(\mathrm{km} / \mathrm{h})$. The data of the seven variables were rated using Mieczkowski's (1985) guideline, and the monthly TCI for Tokyo was calculated and depicted in Fig 1.

\section{Place Fig. 1 here}

As illustrated in Fig. 1, Tokyo's weather is "excellent" in May (83) and June (82). The weather is "very good" from September (78) to December (71); it is also "very good" in January (70), February (76), and April (72). Tokyo offers "good" weather in July (64), August (63), and March (63). According to the TCI results, the 2020 Olympic Games are scheduled in the least suitable time, as they will be held from July 24 to August 9 (16 days). The schedule of the 2020 Paralympic Games, spanning from August 25 to September 6 (16 days), is relatively suitable since September's weather is "very good," whereas it is "good" in August (12 days). Since the total duration of both the 2020 Olympic and Paralympic Games is less than 30 days, the events could be held from May to June, when Tokyo offers an "excellent" climate.

It is acknowledged that along with weather, several other factors-such as coincidences with national leagues and continental competitions-need to be considered to develop a calendar for this mega-event. Moreover, a change from the stereotypical Summer Olympic and Paralympic Games to spring seems unusual and might not be straightforward. Nevertheless, this shift is an adaptive strategy against adverse impacts of climate change, as FIFA implemented successfully in the case of Qatar 2022 World Cup. The traditional summer World Cup has been changed to an autumn Cup to address the undesired effects of extreme weather. This decision is also a more proenvironmental action, as the organizer needs to use less energy and efforts for cooling and ventilation due to optimal weather. 


\section{Conclusion and policy implications}

Apart from the environmental perceptive, any socio-economic burdens of such an adjustment before the announcement of the event's details would be less than cancellation and change of the event calendar, specifically after publicizing the schedule and destination. For example, cancelling international events (e.g. rallies in China and Dakar) due to unfavourable weather may shadow the image of the destination. The discomfort of athletes and visitors caused by severe weather may also affect their satisfaction and loyalty to the destination. Technically, unfavourable weather at an event destination can lead to both handicapped performances (Briki et al., 2016) and health risks for athletes (Mountjoy et al., 2012).

This research letter proposes the following policies to address the adverse consequences of overlooking weather in mega-event management. First, it is recommended that international and national institutions (e.g., FIFA, IOC) invite and engage tourism climate experts at an early stage of planning to get their advice about selection of ideal dates and destinations for events in terms of favourability of weather. As Jennings (2016) articulated IOC used fuzzy rule system to rate hosts of mega-events in the bid procedure. It is recommended to assess the weather of host location based on a technical assessment and allocate a relational weight to the weather condition. Second, it is worthwhile to develop indices to evaluate the weather based on a specific tourism segment or sport activities (de Freitas, Scott, McBoyle, 2008). Due to availability of meteorological parameters for calculation of TCI for Tokyo and its ease of calculation, this study used TCI (Mieczkowski 1985) as one of the most comprehensive metrics which is frequently used for evaluation of weather conditions. Further studies can consider daily data that provides a more precise estimation of TCI (Perch-Nielsen, Amelung \& Knutti, 2010) and also apply more advanced indices such as climate index for tourism (CIT) (de Freitas, Scott, McBoyle, 2008) and fuzzybased tourism climate index (Olya \& Alipour, 2015b).

Third, further research can compare the cost-benefit analysis of applying possible circumstances (e.g. cancelation of the event, shift of schedule based on most favourable weather, change of calendar based on non-meteorological indicators, and sticking on the traditional program) to identify their environmental, socio-economic, and technical impacts. Finally, it is time to apply more innovative, adaptive strategies against climate change, using scientific and technological advances on monitoring and forecasting weather for knowledge-based management of events and 
tourism activities. As Olya and Altinay (2016) proposed, operationalization of weather insurance can serve as a novel service for management of potential risks posed by extreme weather, which may also formulate the desired attitude and behaviour of visitors and participants.

\section{References}

Baldwin, A. (2017). Dakar sixth stage canceled due to extreme weather. Retrieved April 30, 2017, from Thomson Reuters Webpage: http://www.reuters.com/article/us-motor-rally-dakaridUSKBN14R0BQ.

Briki, W., Markman, K. D., Coudevylle, G., Sinnapah, S., \& Hue, O. (2016). Momentum sequence and environmental climate influence levels of perceived psychological momentum within a sport competition. European journal of sport science, 16(3), 350-357.

Blatter, S. (2013). Fifa may have made a "mistake" in awarding the 2022 World Cup to Qatar, according to president Sepp Blatter. Retrieved April 27, 2017, from BBC: http://www.bbc.com/sport/football/24023651.

Chang, P. C., \& Singh, K. K. (1990). Risk management for mega-events: the 1988 Olympic Winter Games. Tourism Management, 11(1), 45-52.

de Freitas, C. R. (2015). Weather and place-based human behavior: recreational preferences and sensitivity. International journal of biometeorology, 59(1), 55-63.

de Freitas, C. R., Scott, D., \& McBoyle, G. (2008). A second generation climate index for tourism (CIT): specification and verification. International Journal of Biometeorology, 52(5), 399-407.

Evans, D. (2017). Rally China cancelled due to storm damage after organisers' request. Retrieved April 27, 2017, from Autosport Media UK: http://www.autosport.com/news/report.php/id/125724.

Gómez Martín, B. M. (2005). Weather, climate and tourism a geographical perspective. Annals of tourism research, 32(3), 571-591.

Jennings, W. (2012). Olympic risks. Palgrave Macmillan.

Jennings, W. (2016). Risk management for the Olympics and Football World Cup. 37. In Frawley, S. (Ed.). (2016). Managing Sport Mega-events. London: Routledge.

Jennings, W., Lodge, M., \& Comfort, L. K. (2012). The Olympic Games: coping with risks and crises at a mega-event. 263-278.

Mieczkowski, Z. (1985). The tourism climatic index: a method of evaluating world climates for tourism. The Canadian Geographer, 29(3), 220-233.

Mountjoy, M., Alonso, J. M., Bergeron, M. F., Dvorak, J., Miller, S., \& Migliorini, S. (2012). Hyperthermic-related challenges in aquatics, athletics, football, tennis and triathlon. British journal of sports medicine, 46(11), 800-804.

Olya, H. G., \& Alipour, H. (2015a). Risk assessment of precipitation and the tourism climate index. Tourism Management, 50, 73-80. 
Olya, H., \& Alipour, H. (2015b). Modeling tourism climate indices through fuzzy logic. Climate Research, 66(1), 49-63.

Olya, H. G., \& Altinay, L. (2016). Asymmetric modeling of intention to purchase tourism weather insurance and loyalty. Journal of Business Research, 69(8), 2791-2800.

Perch-Nielsen, S. L., Amelung, B., \& Knutti, R. (2010). Future climate resources for tourism in Europe based on the daily Tourism Climatic Index. Climatic change, 103(3-4), 363-381.

Toohey, K., \& Taylor, T. (2008). Mega events, fear, and risk: Terrorism at the Olympic Games. Journal of Sport Management, 22(4), 451-469. 


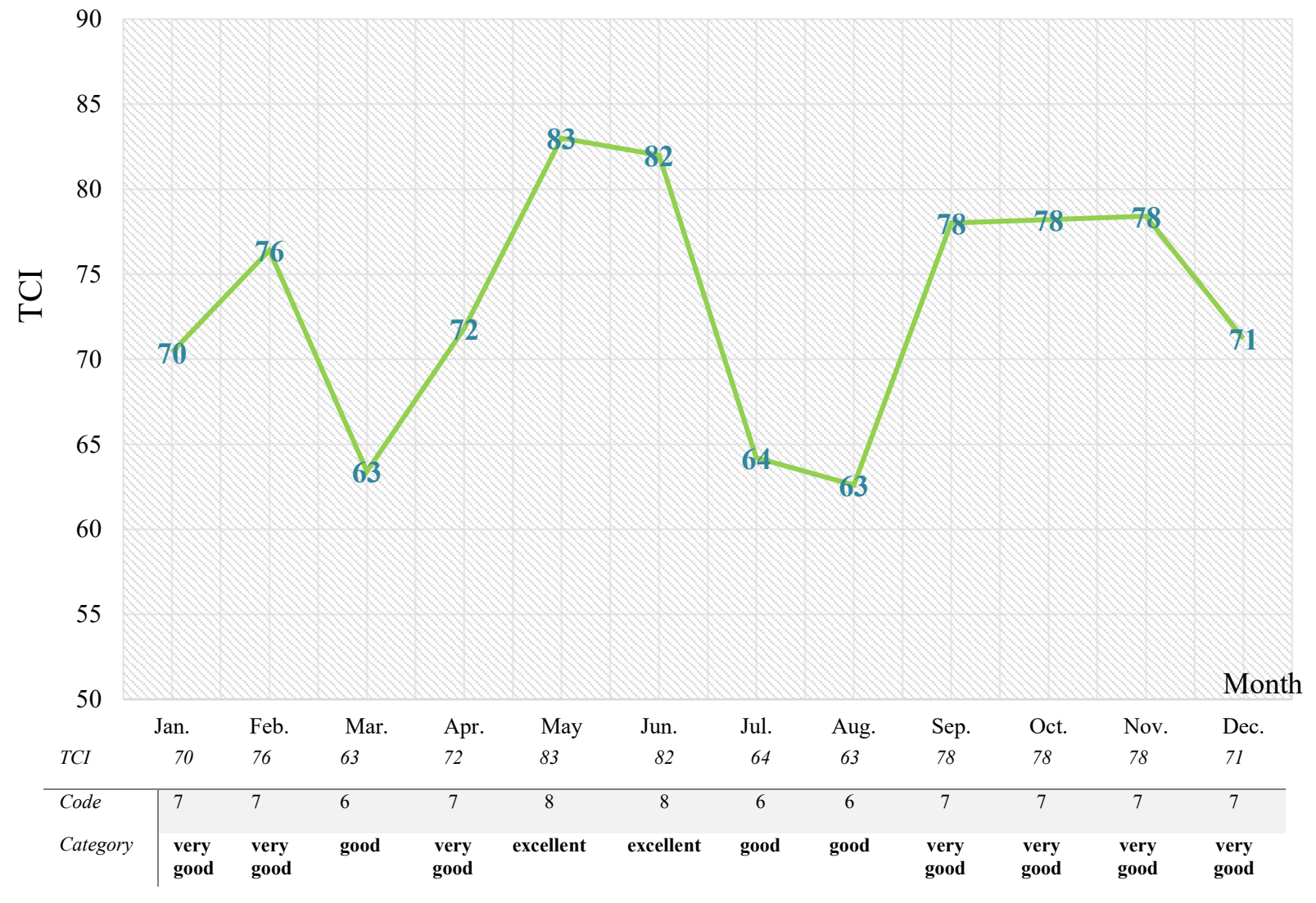

Figure 1. Monthly TCI for Tokyo 